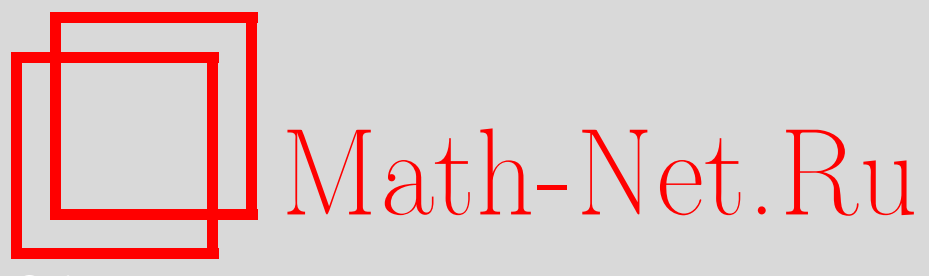

А. М. Асташов, И. В. Асташова, А. В. Бочаров, В. М. Бухштабер, В. А. Васильев, А. М. Вербовецкий, А. М. Вершик, А. П. Веселов, М. М. Виноградов, Л. Витальяно, Р. Ф. Витоло, Ф. Ф. Воронов, В. Г. Кац, И. Косманн-Шварцбах, И. С. Красильщик, И. М. Кричевер, А. П. Крищенко, С. К. Ландо, В. В. Лычагин, М. Марван, В. П. Маслов, А. С. Мищенко, С. П. Новиков, В. Н. Рубцов, А. В. Самохин, А. Б. Сосинский, Дж. Сташеф, Д. Б. Фукс, А. Я. Хелемский, Н. Г. Хорькова, В. Н. Четвериков, А. С. Шварц, Александр Михайлович Виноградов (некролог), УМH, 2020, том 75, выпуск 2, 185-190

DOI: https://doi.org/10.4213/rm9931

Использование Общероссийского математического портала Math-Net.Ru подразумевает, что вы прочитали и согласны с пользовательским соглашением http://www . mathnet.ru/rus/agreement

Параметры загрузки:

IP : 52.205 .19 .152

26 апреля 2023 г., 15:15:10

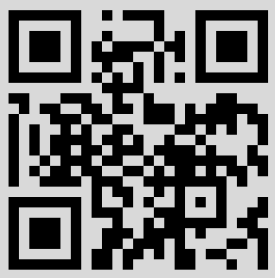




\section{Александр Михайлович Виноградов}

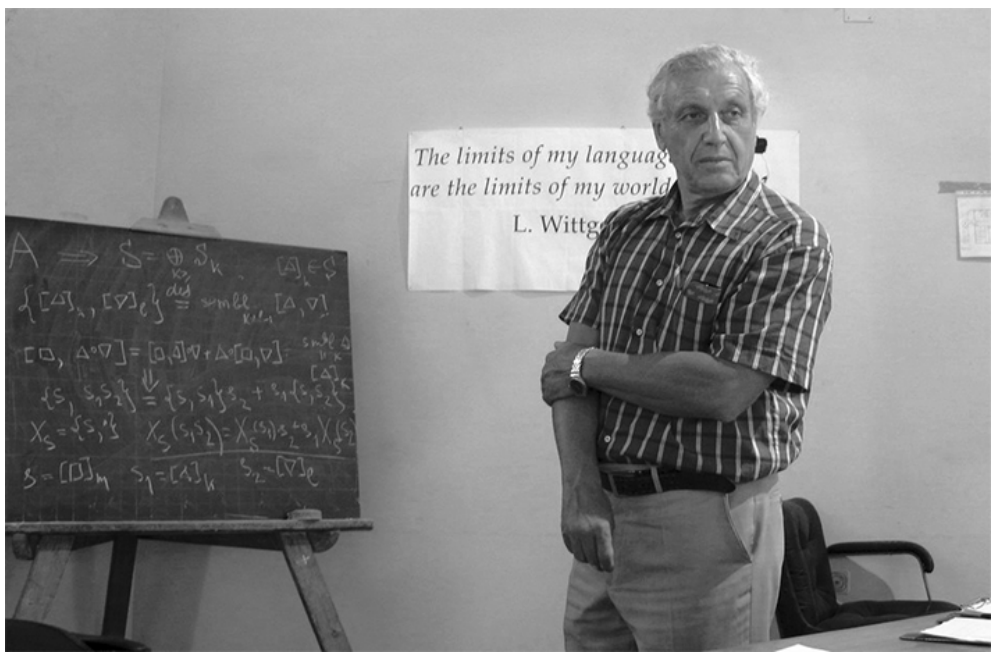

20 сентября 2019 г. ушёл из жизни Александр Михайлович Виноградов, замечательный математик и неординарный человек.

А. М. Виноградов родился 18 февраля 1938 г. в Новороссийске, во время войны был с матерью в эвакуации в Кунгуре (отец служил в армии), затем его родители поселились в подмосковном Кунцеве, которое тогда ещё не было частью Москвы. В 1955 г. он стал студентом механико-математического факультета МГУ, а в 1960-м - аспирантом. После защиты в 1964 г. кандидатской диссертации год преподавал в Московском горном институте, затем по приглашению Н. В. Ефимова, который тогда был деканом, перешёл на кафедру высшей геометрии и топологии мехмата (кафедрой в то время руководил П. С. Александров), где и проработал до своего отъезда в Италию в 1990-м. Доктором физико-математических наук стал в 1984 г. В 1993-2010 гг. был профессором Университета Салерно (Италия).

Ещё будучи студентом второго курса, А.М. Виноградов опубликовал две работы по теории чисел (совместно с Б.Н. Делоне и Д.Б. Фуксом), однако к окончанию университета его интересы меняются: на старших курсах, занимаясь в семинаpe А.С. Шварца, и в аспирантуре он начинает изучать алгебраическую топологию. Его кандидатская диссертация, формальным руководителем которой был В. Г. Болтянский, посвящена гомотопическим свойствам пространства вложений окружности в сферу или шар. Одна из первых работ А. М. Виноградова (1958 г.) была посвящена спектральной последовательности Адамса, которая в то время справедливо считалась вершиной алгебраической топологии. В заметке [1] было заявлено решение задачи Ф. Адамса о связи высших когомологических операций с фильтрацией Адамса в стабильных гомотопических группах сфер. На эту заметку Ф. Адамс написал

DOI: https://doi.org/10.4213/rm9931 
благожелательный отзыв. Задачами алгебраической и дифференциальной топологии А. М. Виноградов занимался до начала 1970-х годов. Той же проблематике был посвящён и научно-исследовательский семинар, который он стал вести с 1967 г.

Второй и последний раз Александр Михайлович кардинально меняет сферу своей математической деятельности на рубеже 1960-1970-х годов. Вдохновлённый идеями Софуса Ли, он начинает продумывать основы геометрической теории дифференциальных уравнений в частных производных. Ознакомившись с работами Д. Спенсера, Х. Гольдшмидта и Д. Квиллена по формальной разрешимости, обращает своё внимание на её алгебраическую и, в частности, когомологическую составляющую.

В 1972 г. в "Докладах АН СССР" появляется его короткая заметка (публиковать длинные тексты в те годы было непросто) "Алгебра логики теории линейных дифференциальных операторов" [2], в которой были построены, как он это называл, основные функторы дифференциального исчисления в коммутативных алгебрах. На четырёх страничках журнального текста было изящно продемонстрировано, что для определения и изучения фундаментальных свойств таких понятий, как векторное поле, дифференциальная форма, джет (струя), линейный дифференциальный оператор и т. п., достаточно категории модулей над коммутативной алгеброй с единицей, а их геометрические прототипы возникают, если в качестве этой алгебры выбрать алгебру гладких функций на многообразии, а в качестве модулей - пространства сечений векторных расслоений над этим многообразием. Позднее расширенный вариант этой заметки был преобразован в первую главу книги [3] и частично вошёл в [4] (уже относительно недавно модернизированная версия теории была опубликована в [5]), а пример её применения к построению алгебраической модели гамильтоновой механики можно найти в [6].

Здесь уместно заметить, что А. М. Виноградов был естественным "математическим полиглотом": он легко переходил с языка алгебры на язык дифференциальной геометрии и часто пользовался “словарём" для - иногда вовсе не тривиального перевода известных в классической дифференциальной геометрии утверждений на язык геометрии бесконечно продолженных уравнений. Такая многоязычность служила для него продуктивным источником содержательных конструкций, определений и утверждений ${ }^{1}$. Его всегда привлекала возможность инвариантного, бескоординатного (и, значит, элегантного) изложения, будь то гамильтонова механика [8] или геометрия [9].

Подход Виноградова к нелинейным дифференциальным уравнениям как геометрическим объектам, с общей теорией и приложениями, подробно изложен в монографиях [3] и [10], а также в статьях [11], [12]. Он объединял бесконечно продолженные уравнения в категорию [13], объекты которой называл диффеотопами (англ. diffiety - differential variety), а аппарат их изучения - вторичным дифференциальным исчислением (англ. secondary calculus) ${ }^{2}$ [14], [15]. Одно из центральных мест в этой теории занимает $\mathscr{C}$-спектральная последовательность (спектральная последовательность Виноградова), которая была анонсирована в [16], а позднее подробно описана в [17]. Член $E_{1}$ этой спектральной последовательности дает единообразный когомологический подход ко многим ранее разрозненным понятиям и утверждениям, включая лагранжев формализм со связями, законы сохранения, косимметрии, теорему Нётер и критерий Гельмгольца в обратной задаче вариационного исчисления (для произвольных нелинейных дифференциальных операторов), позволяя пойти значительно дальше этих классических утверждений. Частным случаем $\mathscr{C}$-спектральной

\footnotetext{
${ }^{1}$ Например, таким образом он пришёл к понятию дифференциального накрытия [7], которое занимает центральное место в нелокальной геометрии дифференциальных уравнений и оказалось крайне важным для понимания ряда структур, связанных с интегрируемыми системами.

${ }^{2}$ По аналогии с вторичным квантованием.
} 
последовательности (для "пустого" уравнения, т. е. пространства бесконечных джетов) является так называемый вариационный бикомплекс.

Результаты статьи [16] были впоследствии обобщены в работах Р.Л. Брайанта и П. А. Гриффитса [18] (на языке внешних дифференциальных систем), А. М. Вербовецкого [19] (с использованием горизонтального комплекса де Рама), Т. Цудзиситы [20]. По своей сути идеи, лежащие в основе построения $\mathscr{C}$-спектральной последовательности, и результаты, естественно вытекающие из этих идей, были первыми шагами к тому, что теперь принято называть когомологической физикой (см., например, статью Дж. Сташефа [21]).

К этой же области относятся важные работы [22] и [23]. В первой из них А. М. Виноградов ввел конструкцию новой скобки на градуированной алгебре линейных преобразований коцепного комплекса. Скобка Виноградова (которую он назвал $L$-коммутатором) кососимметрична и удовлетворяет тождеству Якоби с точностью до кограницы. Конструкция Виноградова предвосхитила общее понятие производной скобки на дифференциальной алгебре Лодэ (или алгебре Лейбница), введенной И. КосманнШварцбах в 1996 г., см. [24]. Скобка Виноградова есть кососимметричная версия производной скобки, построенной по оператору кограницы. Производные скобки и их обобщения играют чрезвычайно важную роль в современных приложениях гомотопических алгебр Ли, алгеброидов Ли и т. п., и работа А. М. Виноградова [22] - одна из пионерских работ в этом направлении.

А. М. Виноградов, в частности, показал, что классические скобки Схоутена (на поливекторных полях) и Нийенхейса (на векторных полях с коэффициентами в дифференциальных формах) являются ограничениями его скобки на соответствующие подалгебры супердифференциальных операторов на внешней алгебре форм. В последующей работе [23], совместной с А. Кабрас, он применил эти результаты к пуассоновой геометрии. В этой статье были построены новые примеры дифференциальногеометрических производных скобок.

В современных приложениях возникают обобщения (супер)алгебр Ли с "высшими скобками" (т.е. содержащими $n>2$ аргументов). Помимо сильно-гомотопических алгебр Ли (или $L_{\infty}$-алгебр) Лады и Сташефа таковы “алгебры Филиппова". Анализу и сопоставлению этих структур были посвящены работы [25]-[27], написанные А. М. Виноградовым с соавторами.

Следует отметить, что научные интересы Александра Михайловича всегда очень сильно мотивировались сложными и важными проблемами современной физики - от динамики звуковых пучков [28] до уравнений магнитогидродинамики (так называемых уравнений Кадомцева-Погуце, используемых в теории устойчивости высокотемпературной плазмы в токамаках) [29]. Математическому осмыслению фундаментального физического понятия наблюдаемой уделено много внимания в книге [4], написанной А. М. Виноградовым в соавторстве с участниками его семинара и вышедшей под псевдонимом Джет Неструев.

Чем бы ни занимался А. М. Виноградов - геометрией уравнений, скобками Схоутена и Нийенхейса [22], [23], математическими вопросами теории гравитации [30]-[32], $n$-арными обобщениями алгебр Ли [25]-[27] или структурным анализом последних [33], [34], - все его работы объединяет неортодоксальность подхода, глубина и нетривиальность результатов. Его печатное наследие составляют более сотни статей и десять монографий.

Научная деятельность А. М. Виноградова не ограничивалась кабинетной работой. В течение многих лет он вёл научно-исследовательский семинар на мехмате МГУ, состоявший из двух частей, математической и физической, и ставший заметным явлением московской математической жизни 1960-1980-х годов. Он воспитал плеяду учеников (в России, Италии, Швейцарии, Польше), 19 из них защитили кандидатские диссертации, 6 стали докторами наук и один - членом-корреспондентом РАН. По его 
инициативе и под его руководством в Италии, России и Польше проходили диффеотопические школы (Diffiety Schools). Александр Михайлович был душой серии камерных конференций "Современная геометрия" (Current Geometry), проводившихся в Италии с 2000 по 2010 г., а также представительной московской конференции "Вторичное дифференциальное исчисление и когомологическая физика" (Secondary Calculus and Cohomological Physics, 1997), труды которой были опубликованы в [15].

Он был одним из инициаторов и активным участником создания Международного института математической физики им. Э. Шрёдингера в Вене (ESI), а также журнала Journal of Differential Geometry and its Applications, членом редколлегии которого состоял до последних дней. В 1985 г. А. М. Виноградов создал лабораторию в Институте программных систем в Переславле-Залесском и был её научным руководителем до своего отъезда в Италию. В лаборатории исследовались различные аспекты геометрии дифференциальных уравнений. Он читал лекции ребятам, которых не приняли на мехмат из-за их еврейского происхождения (Александр Михайлович называл это "университетом дружбы народов").

Он был разносторонним человеком - играл на скрипке, писал стихи на итальянском, выступал за сборную мехмата по водному поло, был азартным футболистом. Но главным для него была, безусловно, математика.

Александр Михайлович продолжает жить в своих работах, в памяти учеников, родных и друзей.

A.M. Асташов, И. В. Асташова, А.В. Бочаров, В.М. Бухитабер, В.А. Васильев, А.М. Вербовецкий, А.М. Вершик, А.П. Веселов, М.М. Виноградов, Л. Витальяно, Р.Ф. Витоло, Ф.Ф. Воронов, В.Г. Кач, И. Косманн-Швари,ах, И. С. Красильщик, И. М. Кричевер, А.П. Крищенко, С. К. Ландо, В.В. Лычагин, М. Марван, В.П. Маслов, А.С. Мищенко, С.П. Новиков, В.Н. Руби,ов, А.В. Самохин, А.Б. Сосинский, Дж. Сташеф, Д. Б. Фукс, А. Я. Хелемский, Н.Г. Хорькова, В.Н. Четвериков, А.С. Швари,

\section{Список литературы}

[1] А. М. Виноградов, "О спектральной последовательности Адамса", Докл. AH CCCP, 133:5 (1960), 999-1002; англ. пер.: A. M. Vinogradov, "On Adams' spectral sequence", Soviet Math. Dokl., 1 (1960), 910-913.

[2] А. М. Виноградов, “Алгебра логики линейных дифференциальных операторов”, Докл. АН СССР, 205:5 (1972), 1025-1028; англ. пер.: А. M. Vinogradov, "The logic algebra for the theory of linear differential operators", Soviet Math. Dokl., 13 (1960), 1058-1062.

[3] А.М. Виноградов, И.С. Красильщик, В.В. Лычагин, Введение в геометрию нелинейных дифберенииальных уравнений, Наука, М., 1986, 336 с.

[4] Дж. Неструев, Гладкие многообразия и наблюдаемые, МЦНМО, М., 2000, 300 с.; англ. пер.: J. Nestruev, Smooth manifolds and observables, Grad. Texts in Math., 220, Springer-Verlag, New York, 2003, xiv+222 pp.

[5] A. M. Vinogradov, "Logic of differential calculus and the zoo of geometric structures", Geometry of jets and fields, Banach Center Publ., 110, Polish Acad. Sci. Inst. Math., Warsaw, 2016, 257-285.

[6] А.М. Виноградов, И.С. Красильщик, "Что такое гамильтонов формализм?", УМH, 30:1(181) (1975), 173-198; англ. пер.: A. M. Vinogradov, I. S. Krasil'shchik, "What is the Hamiltonian formalism?", Russian Math. Surveys, 30:1 (1975), 177-202. 
[7] I. S. Krasil'shchik, A. M. Vinogradov, "Nonlocal trends in the geometry of differential equations: symmetries, conservation laws, and Bäcklund transformations", Acta Appl. Math., 15:1-2 (1989), 161-209.

[8] А. М. Виноградов, Б.А. Купершмидт, "Структура гамильтоновой механики", УМН, 32:4(196) (1977), 175-236; англ. пер.: А. M. Vinogradov, B. A. Kupershmidt, "The structures of Hamiltonian mechanics", Russian Math. Surveys, 32:4 (1977), $177-243$.

[9] Д. В. Алексеевский, А. М. Виноградов, В. В. Лычагин, "Основные идеи и понятия дифференциальной геометрии", Геометрия - 1, Итоги науки и техн. Сер. Соврем. пробл. матем. Фундам. направления, 28, ВИНИТИ, М., 1988, 5-289; англ. пер.: D. V. Alekseevskij, A. M. Vinogradov, V. V. Lychagin, "Basic ideas and concepts of differential geometry", Geometry I, Encycl. Math. Sci., 28, 1991, 1-264.

[10] А. М. Виноградов, И.С. Красильщик (ред.), Симметрии и законы сохранения уравнений математической физики, 2-е изд., испр., Факториал Пресс, М., 2005, 380 с.; англ. пер. 1-го изд.: I. S. Krasil'shchik, A. M. Vinogradov (eds.), Symmetries and conservation laws for differential equations of mathematical physics, Transl. Math. Monogr., 182, Amer. Math. Soc., Providence, RI, 1999, xiv+333 pp.

[11] A. M. Vinogradov, "Local symmetries and conservation laws", Acta Appl. Math., 2:1 (1984), 21-78.

[12] А. М. Виноградов, "Геометрия нелинейных дифференциальных уравнений”, Итоги науки и техн. Сер. Пробл. геом., 11, ВИНИТИ, М., 1980, 89-134; англ. пер.: A. M. Vinogradov, "The geometry of nonlinear differential equations", J. Soviet Math., 17:1 (1981), 1624-1649.

[13] А.М. Виноградов, "Категория нелинейных дифференциальных уравнений”, Уравнения на многообразиях, Новое в глобальном анализе, Изд-во Воронеж. гос. ун-та, Воронеж, 1982, 26-51; англ. пер.: А. M. Vinogradov, "Category of nonlinear differential equations", Global analysis - studies and applications I, Lecture Notes in Math., 1108, Amer. Math. Soc., Providence, RI, 1984, 77-102.

[14] A. Vinogradov, "Introduction to secondary calculus", Secondary calculus and cohomological physics (Moscow, 1997), Contemp. Math., 219, Amer. Math. Soc., Providence, RI, 1998, 241-272.

[15] M. Henneaux, I. S. Krasil'shchik, A. M. Vinogradov (eds.), Secondary calculus and cohomological physics (Moscow, 1997), Contemp. Math., 219, Amer. Math. Soc., Providence, RI, 1998, xiv+287 pp.

[16] А. М. Виноградов, "Одна спектральная последовательность, связанная с нелинейным дифференциальным уравнением и алгебро-геометрические основания лагранжевой теории поля со связями", Докл. АН ССCP, 238:5 (1978), 1028-1031; англ. пер.: A.M. Vinogradov, "A spectral sequence associated with a nonlinear differential equation, and algebro-geometric foundations of Lagrangian field theory with constraints", Soviet Math. Dokl., 19 (1978), 144-148.

[17] A. M. Vinogradov, "The $\mathscr{C}$-spectral sequence, Lagrangian formalism, and conservation laws. I. The linear theory", J. Math. Anal. Appl., 100:1 (1984), 1-40; "II. The nonlinear theory", 41-129.

[18] R. L. Bryant, P.A. Griffiths, "Characteristic cohomology of differential systems. I. General theory", J. Amer. Math. Soc., 8:3 (1995), 507-596.

[19] A. Verbovetsky, "Notes on the horizontal cohomology", Secondary calculus and cohomological physics (Moscow, 1997), Contemp. Math., 219, Amer. Math. Soc., Providence, RI, 1998, 211-231.

[20] T. Tsujishita, "On variation bicomplexes associated to differential equations", Osaka Math. J., 19:2 (1982), 311-363. 
[21] J. Stasheff, "The (secret?) homological algebra of the Batalin-Vilkovisky approach", Secondary calculus and cohomological physics (Moscow, 1997), Contemp. Math., 219, Amer. Math. Soc., Providence, RI, 1998, 195-210.

[22] А. М. Виноградов, "Объединение скобок Схоутена и Нийенхейса, когомологии и супердифференциальные операторы", Матем. заметки, 47:6 (1990), 138-140.

[23] A. Cabras, A. M Vinogradov, "Extensions of the Poisson bracket to differential forms and multi-vector fields", J. Geom. Phys., 9:1 (1992), 75-100.

[24] Y. Kosmann-Schwarzbach, "From Poisson algebras to Gerstenhaber algebras", Ann. Inst. Fourier (Grenoble), 46:5 (1996), 1243-1274.

[25] P. W. Michor, A. M. Vinogradov, " $n$-ary Lie and associative algebras", Geometrical structures for physical theories. II (Vietri, 1996), Rend. Sem. Mat. Univ. Politec. Torino, 54:4 (1996), 373-392.

[26] G. Marmo, G. Vilasi, A.M. Vinogradov, "The local structure of $n$-Poisson and n-Jacobi manifolds", J. Geom. Phys., 25:1-2 (1998), 141-182.

[27] A. M. Vinogradov, M. M. Vinogradov, "Graded multiple analogs of Lie algebras", Acta Appl. Math., 72:1-2 (2002), 183-197.

[28] А. М. Виноградов, Е. М. Воробьев, "Применение симметрии для нахождения точных решений уравнения Заболотской-Хохлова", Акустич. журн., 22:1 (1976), $23-27$.

[29] V. N. Gusyatnikova, A. V. Samokhin, V.S. Titov, A. M. Vinogradov, V.A. Yumaguzhin, "Symmetries and conservation laws of Kadomtsev-Pogutse equations (their computation and first applications)", Acta Appl. Math., 15:1-2 (1989), 23-64.

[30] G. Sparano, G. Vilasi, A. M. Vinogradov, "Vacuum Einstein metrics with bidimensional Killing leaves. I. Local aspects", Differential Geom. Appl., 16:2 (2002), 95-120.

[31] G. Sparano, G. Vilasi, A. M. Vinogradov, "Vacuum Einstein metrics with bidimensional Killing leaves. II. Global aspects", Differential Geom. Appl., 17:1 (2002), 15-35.

[32] G. Sparano, G. Vilasi, A. M. Vinogradov, "Gravitational fields with a non-Abelian, bidimensional Lie algebra of symmetries", Phys. Lett. B, 513:1-2 (2001), 142-146.

[33] A. M. Vinogradov, "Particle-like structure of Lie algebras", J. Math. Phys., 58:7 (2017), 071703, 49 pp.

[34] A. M. Vinogradov, "Particle-like structure of coaxial Lie algebras", J. Math. Phys., 59:1 (2018), 011703, 42 pp. 